\title{
Long Term Effect on Adjacent Segment Motion after Posterior Cervical Foraminotomy
}

\author{
Tack Geun Cho', Young Baeg Kim², Seung Won Park ${ }^{2}$

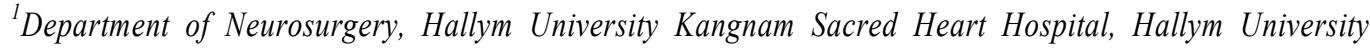 \\ College of Medicine, Seoul, Korea \\ ${ }^{2}$ Department of Neurosurgery, Spine Center, Chung-Ang University Hospital, Chung-Ang University \\ School of Medicine, Seoul, Korea
}

\begin{abstract}
Objective: Posterior cervical foraminotomy (PCF) is a motion-preserving surgical technique. The objective was to determine whether PCF alter cervical motion as a long-term influence.

Methods: Thirty one patients who followed up more than 36 months after PCF for cervical radiculopathy from January 2004 to September 2008 were enrolled in this study. The range of motion (ROM) of whole cervical spine, the operated segment, the cranial and the caudal adjacent segment were obtained. The clinical result and the change of ROMs were compared with those in the patients performed anterior cervical discectomy and fusion (ACDF) during the same period.

Results: In PCF group, the ROM of whole cervical spine had no significant difference in statistically at preoperative and last follow up. The operated segment ROM was significantly decreased from $11.02 \pm 5.72$ to $8.82 \pm 6.65(p<0.05)$. The ROM of cranial adjacent segment was slightly increased from $10.42 \pm 5.13$ to $11.02 \pm 5.41$ and the ROM of caudal adjacent segment was decreased from $9.44 \pm 6.26$ to $8.73 \pm 5.92$, however these data were not meaningful statistically. In ACDF group, the operated ROM was decreased and unlike in PCF group, especially the ROM of caudal adjacent segment was increased from $9.39 \pm 4.21$ to $11.33 \pm 5.07$ ( $p<0.01)$.

Conclusion: As part of the long-term effects of PCF on cervical motion, the operated segment motions decreased but were preserved after PCF. However, unlikely after ACDF, the ROMs of the adjacent segment did not increase after PCF. PCF, by maintaining the motion of the operated segment, imposes less stress on the adjacent segments. This may be one of its advantages.
\end{abstract}

Key Words: Posterior cervical foraminotomy $\cdot$ Anterior cervical discectomy and fusion $\cdot$ Adjacent segment $\cdot$ Range of motion

\section{INTRODUCTION}

There are various methods of managing cervical radiculopathy. The symptoms generally improve after conservative treatment ${ }^{2,3)}$, however short-term disability has been known to be improved by surgical treatment ${ }^{6,17}$. Surgical treatment of cervical radiculopathy has been mainly classified into ante-

- Received: February 26, 2014 - Revised: March 19, 2014

- Accepted: March 19, 2014

Corresponding Author: Young Baeg Kim, MD, PhD

Department of Neurosurgery, Spine Center, Chung-Ang University

Hospital 224-1, Heukseok-dong, Dongjak-gu, Seoul 156-755, Korea

Tel: +82-2-6299-1595, Fax: +82-2-821-8409

E-mail: ybkim1218@cau.ac.kr

(2This is an Open Access article distributed under the terms of the Creative

Commons Attribution Non-Commercial License (http://creativecommons.org/

licenses/by-nc/3.0/) which permits unrestricted non-commercial use, distribution,

and reproduction in any medium, provided the original work is properly cited. rior and posterior approaches. Anterior cervical discectomy and fusion (ACDF) has the advantages of easier exposure, wider exposure of the disc space, and less patient discomfort ${ }^{18)}$. However it has a risk of adjacent segment disease due to the fixation of the vertebral body ${ }^{12)}$.

The posterior cervical foraminotomy (PCF) to the treatment of the cervical spine was pioneered by Frykholm and further modified by Scoville et al. and Whitcombe ${ }^{4)}$. It has the advantages of easier access to the eccentrically located disc fragment, less risk of post-operative dysphagia and hoarseness due to the non-retraction of the esophagus and the laryngeal nerve, and the absence of the risk of complications, such as pseudo-arthrosis and graft subsidence, which may occur after $\mathrm{ACDF}^{4)}$. Many studies have reported the clinical efficacy of PCF and that more than $90 \%$ of patients who underwent PCF showed a satisfactory prognosis ${ }^{10,14,23,24)}$. In addition, unlike ACDF, PCF has the theoretical advantage of maintaining the motion of the operated segment. Few long-term 

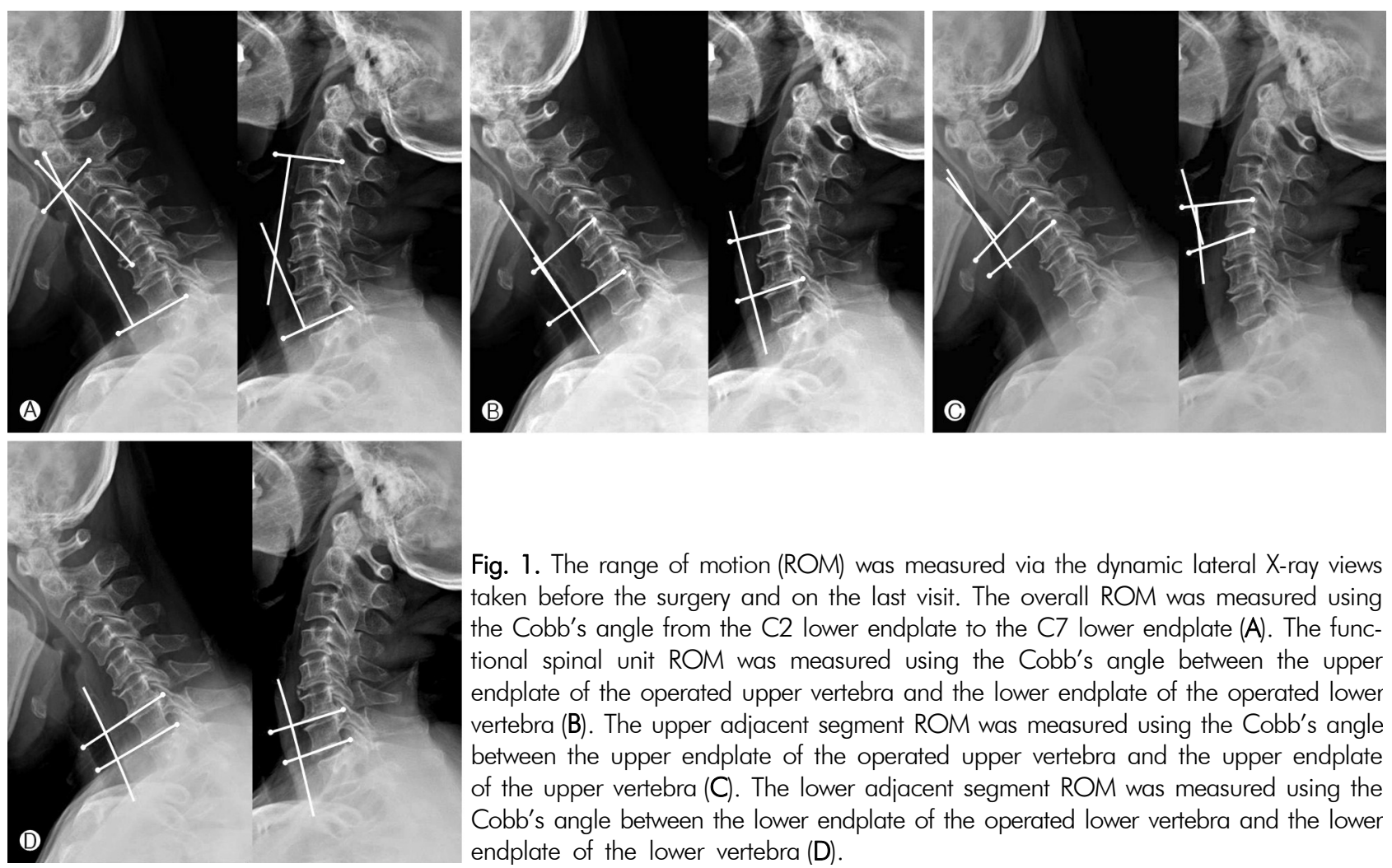

Fig. 1. The range of motion (ROM) was measured via the dynamic lateral $X$-ray views taken before the surgery and on the last visit. The overall ROM was measured using the Cobb's angle from the C2 lower endplate to the C7 lower endplate (A). The functional spinal unit ROM was measured using the Cobb's angle between the upper endplate of the operated upper vertebra and the lower endplate of the operated lower vertebra (B). The upper adjacent segment ROM was measured using the Cobb's angle between the upper endplate of the operated upper vertebra and the upper endplate of the upper vertebra $(C)$. The lower adjacent segment ROM was measured using the Cobb's angle between the lower endplate of the operated lower vertebra and the lower endplate of the lower vertebra (D).

studies have conducted, however, on the effect of PCF on the motions of the adjacent segments and the operated segment. Accordingly, this study was conducted to investigate the longterm effect of PCF on cervical motion.

\section{MATERIALS AND METHODS}

This study was conducted on patients who underwent C4-5, 5-6, or 6-7 single-level unilateral PCF due to cervical radiculopathy caused by disc herniation or foraminal stenosis from January 2004 to November 2008. Those who had cervical instability or a history of cervical surgery were excluded from the subjects, and those who were followed up for 36 months or longer were included among the subjects.

The patients' gender, age, follow-up duration, surgery level, and clinical outcome were reviewed. The clinical outcome was assessed arm pain using the Numerical rating scale (NRS) measured before the surgery and on the last visit. The overall range of motion (ROM) of the cervical region, the FSU (functional spinal unit) ROM, and the ROM of the adjacent segment in all the patients were measured.

The ROM was measured via the dynamic lateral X-ray views taken before the surgery and on the last visit. The overall ROM was measured using the Cobb's angle from the C2 lower endplate to the C7 lower endplate (Fig. 1A). The FSU ROM was measured using the Cobb's angle between the upper endplate of the operated upper vertebra and the lower endplate of the operated lower vertebra (Fig. 1B). The upper adjacent segment ROM was measured using the Cobb's angle between the upper endplate of the operated upper vertebra and the upper endplate of the upper vertebra (Fig. 1C). The lower adjacent segment ROM was measured using the Cobb's angle between the lower endplate of the operated lower vertebra and the lower endplate of the lower vertebra (Fig. 1D).

The aforementioned parameters were also measured in the patients who were followed up for 36 months or longer, from among the patients who underwent one-level ACDF for cervical $H N P$ in the same period. The data were analyzed via a paired t-test and an independent $\mathrm{t}$-test, and considered statistically significant when $p<0.05$. The values were presented as mean $\pm S D$ values.

\section{RESULTS}

The PCF group consisted of 20 male (64.5\%) and 11 female (35.5\%) patients. Their mean age and follow-up duration were $52.45 \pm 9.65$ years and $62.61 \pm 19.90$ (36-92) months, respectively. Their NRS was $7.00 \pm 1.69$ before the surgery 
Table 1. Summary of baseline characteristics

\begin{tabular}{lllc}
\hline \hline & \multicolumn{1}{c}{ PCF } & ACDF & p-value \\
\hline Sex (male : female) & $20: 11$ & $17: 13$ & $\mathrm{~ns}$ \\
Age & $52.45 \pm 9.65$ & $49.73 \pm 10.41$ & $\mathrm{~ns}$ \\
F/U periods (months) & $62.61 \pm 19.90,(36-92)$ & $61.22 \pm 20.22,(36-92)$ & $\mathrm{ns}$ \\
NRS (Preop. $\rightarrow$ Postop.) & $7.00 \pm 1.69 \rightarrow 2.38 \pm 2.87$ & $7.00 \pm 1.51 \rightarrow 2.28 \pm 3.07$ & $\mathrm{~ns}$ \\
Duration of Sx. (months) & $6.1 \pm 2.8$ & $5.9 \pm 2.6$ & $\mathrm{~ns}$ \\
Operated time (mins) & $79 \pm 28$ & $91 \pm 21$ & $\underline{\underline{0.05}}$ \\
Diagnosis & & & $\underline{0.000}$ \\
$\quad$ HNP & 3 & 24 & \\
HNP / c stenosis & 7 & 6 & \\
Foraminal stenosis & 21 & 0 & \\
\hline
\end{tabular}

$\mathrm{PCF}=$ posterior cervical foraminotomy; $\mathrm{ACDF}=$ anterior cervical discectomy and fusion; preop.=pre-operative; postop.=post-operative; NRS $=$ Numerical rating scale

Table 2. Affected level in PCF and ACDF

\begin{tabular}{lccc}
\hline & PCF & ACDF & p-value \\
\hline Affected level & & & $<0.05$ \\
C4-5 & $2(6.5 \%)$ & $14(46.7 \%)$ & \\
C5-6 & $13(41.9 \%)$ & $14(46.7 \%)$ & \\
C6-7 & $16(51.6 \%)$ & $2(6.7 \%)$ & \\
\hline
\end{tabular}

$\mathrm{PCF}=$ posterior cervical foraminotomy; $\mathrm{ACDF}=$ anterior cervical discectomy and fusion

and 2.38 \pm 2.87 after the surgery. The ACDF group consisted of 17 male and 13 female patients. Their mean age and follow-up duration were $49.73 \pm 10.41$ years and $61.22 \pm 20.22$ (36-92) months, respectively. Their NRS was $7.00 \pm 1.51$ before the surgery and $2.28 \pm 3.07$ after the surgery. Differences in the sex ratio, mean age, follow-up duration, and NRS between the two groups were not significant (Table 1).

As for the operated level, the PCF group had C4-5 2 cases (6.5\%), C5-6 13 cases (41.9\%), and C6-7 16 cases (51.6\%), whereas the ACDF group had C4-5 14 cases (46.7\%), C5-6 14 cases (46.7\%), and C6-7 2 cases (6.7\%). It was statistically significant between the two groups $(\mathrm{p}<0.05)$ (Table 2).

The overall ROM in the PCF group was $43.66 \pm 12.59$ before the surgery and $41.04 \pm 11.56$ after the surgery. The results showed a decrease, though it was not statistically significant. In the ACDF group, the overall ROM was 43.52 \pm 16.12 before the surgery and $40.40 \pm 13.98$ after the surgery. The results showed a decrease, though it was statistically insignificant (Table 3).

The FSU ROM in the PCF group was $11.02 \pm 5.72$ before the surgery and $8.82 \pm 6.65$ after the surgery. The results showed a statistically significant decrease $(p<0.05)$. In the ACDF group, the overall ROM was $11.86 \pm 4.60$ before the
Table 3. Pre and post-operative cervical overall range of motion in PCF and ACDF

\begin{tabular}{lcc}
\hline \hline \multicolumn{1}{c}{ Overall ROM } & PCF & ACDF \\
\hline Preoperative (degree) & $43.66 \pm 12.59$ & $43.52 \pm 16.12$ \\
Last follow up (degree) & $41.04 \pm 11.56$ & $40.40 \pm 13.98$ \\
p-value & $>0.05$ & $>0.05$ \\
\hline
\end{tabular}

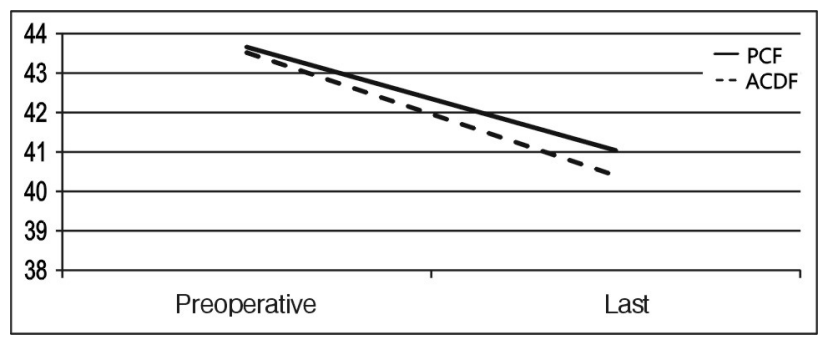

$\mathrm{ROM}=$ range of motion; $\mathrm{PCF}=$ posterior cervical foraminotomy; $\mathrm{ACDF}=$ anterior cervical discectomy and fusion

surgery and $0.94 \pm 0.54$ after the surgery. The results showed a statistically significant decrease $(p=0.000)$ (Table 4).

The upper segment ROM in the PCF group was $10.42 \pm$ 5.13 before the surgery and $11.02 \pm 5.41$ after the surgery, which showed no statistically significant difference. In the ACDF group, the upper segment ROM was $10.32 \pm 5.82$ before the surgery and $11.25 \pm 5.92$ after the surgery, which showed an increase, though it was not statistically significant (Table 5).

The lower segment ROM in the PCF group was 9.44 \pm 6.26 before the surgery and $8.73 \pm 5.92$ after the surgery, which showed no statistically significant difference. In the ACDF group, the lower segment ROM was $9.39 \pm 4.21$ before the surgery and $11.33 \pm 5.07$ after the surgery, which showed a statistically significant increase $(\mathrm{p}<0.01)$ (Table 6). 
Table 4. Pre and post-operative functional spinal unit range of motion in PCF and ACDF

\begin{tabular}{lcc}
\hline \multicolumn{1}{c}{ Overall ROM } & PCF & ACDF \\
\hline Preoperative (degree) & $43.66 \pm 12.59$ & $43.52 \pm 16.12$ \\
Last follow up (degree) & $41.04 \pm 11.56$ & $40.40 \pm 13.98$ \\
p-value & $>0.05$ & $>0.05$ \\
\hline
\end{tabular}

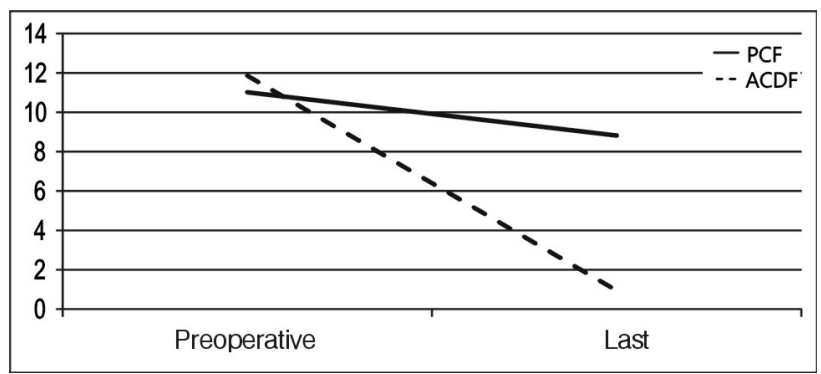

$\mathrm{ROM}=$ range of motion; $\mathrm{PCF}=$ posterior cervical foraminotomy; $\mathrm{ACDF}=$ anterior cervical discectomy and fusion

Table 5. Pre and post-operative upper segment range of motion in PCF and ACDF

\begin{tabular}{lcc}
\hline \hline \multicolumn{1}{c}{ Upper segment ROM } & PCF & ACDF \\
\hline Preoperative (degree) & $10.42 \pm 5.13$ & $10.32 \pm 5.82$ \\
Last follow up (degree) & $11.02 \pm 5.41$ & $11.25 \pm 5.92$ \\
p-value & $>0.05$ & $>0.05$ \\
\hline
\end{tabular}

\begin{tabular}{r|r|}
\hline 12 & \\
11.5 & \\
10.5 & \\
10 & \\
9.5 & \\
9 & \\
\hline 8.5 & \\
8 & \\
& \\
\end{tabular}

$\mathrm{ROM}=$ range of motion; $\mathrm{PCF}=$ posterior cervical foraminotomy; $\mathrm{ACDF}=$ anterior cervical discectomy and fusion

\section{DISCUSSION}

It has been reported that $92 \%$ of patients who had undergone ACDF had radiological degenerative changes in their adjacent segment for 15 years after their surgery, but that only $6.1-16.9 \%$ of such patients had clinical symptoms ${ }^{9,13,26}$. It has also been reported that each year. 2.9\% of patients who had undergone anterior cervical arthrodesis had symptomatic adjacent segment disease, so that the disease occurred in approximately $25.6 \%$ of the patients 10 years later ${ }^{12}$. Thus, adjacent segment degeneration has been reported to even-
Table 6. Pre and post-operative lower segment range of motion in PCF and ACDF

\begin{tabular}{lcc}
\hline \hline \multicolumn{1}{c}{ Lower segment ROM } & PCF & ACDF \\
\hline Preoperative (degree) & $9.44 \pm 6.26$ & $9.39 \pm 4.21$ \\
Last follow up (degree) & $8.73 \pm 5.92$ & $11.33 \pm 5.07$ \\
p-value & $>0.05$ & $<0.01$
\end{tabular}

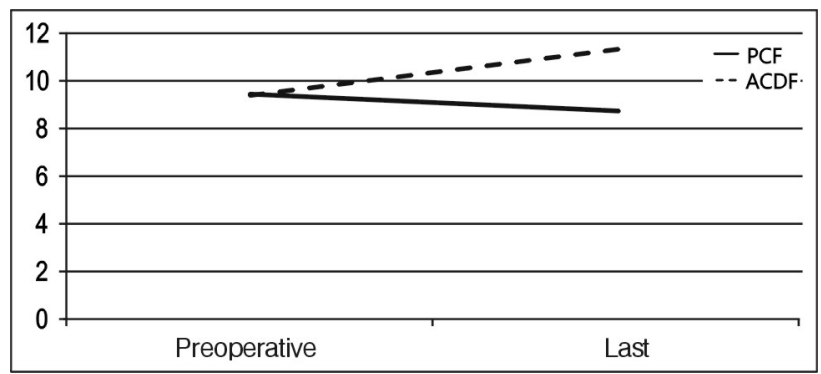

$\mathrm{ROM}=$ range of motion; $\mathrm{PCF}=$ posterior cervical foraminotomy; $\mathrm{ACDF}=$ anterior cervical discectomy and fusion

tually occur after spinal fusion ${ }^{8,12)}$. On the contrary, another study reported that ACDF had no correlation with adjacent segment disease accompanied by symptoms, although it deteriorated to adjacent segment degeneration ${ }^{20}$.

It has been reported that the incidence rate of clinically significant adjacent segment disease was higher in patients who had undergone fusion for cervical HNP than in those who had not undergone fusion ${ }^{16}$. In addition, the rate of the adjacent segment degeneration that was radiologically measured after soft disc herniation surgery was reportedly lower in patients who had undergone posterior foraminotomy than in patients who had undergone fusion ${ }^{11}$. Studies on adjacent segment disease after posterior cervical foraminotomy have been reported ${ }^{4,22)}$, but no study has been conducted on the change in the ROM of the adjacent segment after PCF.

In this study, as no significant difference in the genders, ages, and follow-up durations was found between the PCF group and the ACDF group. Thus, these factors were not as confounding factors and did not affect the results. The post-operative NRS decreased to $2.38 \pm 2.87$ and $2.28 \pm 3.07$ in the two groups, respectively. The results of the clinical assessment of the post-operative pain improvement showed that it was not correlated with the surgical method. The operation time was slightly longer in the ACDF group than in the PCF group, though. This was likely due to the performance of the fixation using the plate in the single-level fusion at that time, unlike in the cage-alone fusion that is currently used in the one-level fusion.

It has been reported that the surgical method varied depending on the site of the occurrence of the soft disc herniation, and that anterior fusion was preferred in the case of 
a central lesion, whereas PCF was preferred in the case of a lateral lesion ${ }^{16}$. In this study, a difference in the diagnoses was shown between the PCF group and the ACDF group. In the PCF group, there were some HNP patients, but $68 \%$ of the patients were foraminal stenosis patients. In the ACDF group, $80 \%$ of the patients were HNP patients, but there was no foraminal stenosis patient. These indicate that ACDF and PCF have different indications. That is, they are treatment methods for different diseases. As for the surgery site, the PCF group had 93.5\% C6-7 and 5-6, whereas the ACDF group had $93.4 \%$ C4-5 and 5-6. These results show that there were fewer cases of foraminal stenosis and lateral HNP in C4-5 than in the lower segments, and more cases of lateral HNP and foraminal stenosis in C6-7 than in the central HNP. It has been reported that the HNP direction varied depending on the shape of the intervertebral disc ${ }^{25}$. In addition, various causative factors, such as the axial rotation, lateral bending, and difference in the ROM for flexion and extension, are likely to be involved, depending on the PLL shape, or vertebral body shape. Thus, further study is required.

The ROM of the cervical spine decreases linearly with increasing age. Flexion movements are less affected by age than are extension movements. Most cases have shown that decreases depended on the reduction of the extension $\operatorname{ROM}^{15,27}$. In this study, although the overall ROMs of the two groups did not significantly differ, they decreased as time passed by. This is likely to be natural course during the aging process.

In this study, the ROM of the operated site decreased as expected because bone union was performed in the ACDF group. It also significantly decreased in the PCF group. This result is likely to have been due to a few factors. First, the lamina and facet could have been partially injured during the surgery, and the subsequent scar formation might have affected the ROM. Second, the blood flow or nutrient supply could have been reduced due to the injury of the soft tissue after the surgery, which leads to faster progression of degenerative change, and could have eventually decreased the ROM. In this study, the ROM of the operated site decreased from $11.02 \pm 5.72$ to $8.82 \pm 6.65$ after PCF, however the important thing was that the motion was maintained.

The ROM of the adjacent segment in the PCF group before the surgery did not significantly differ after the surgery, but the lower segment ROM in the ACDF group significantly increased after the surgery. Adjacent segment degeneration might have occurred in the ACDF group due to the physical stress applied to the adjacent segment via the motion loss of the operated site during the cervical movement. In this study, the lower segment ROM significantly increased in proportion to the increased upper segment ROM. Vedantam A et al. reported that in their study, the superior adjacent segment ROM increased by $70 \%$, but the inferior adjacent segment ROM increased by $110 \%$ after $\mathrm{ACDF}^{21)}$. It has been reported that in a study, the ROM of the adjacent site increased through a compensation mechanism that maintained the overall ROM even if the ROM of the operated site decreased after the fusion, and that the lower segment ROM after the surgery significantly increased because the lower segment is attributed more to the overall ROM than is the upper segment ${ }^{1,5,7,19)}$.

The ROM of the operated segment was maintained in the PCF group despite the decreased ROM. It is likely that the ROM of the adjacent segment did not increase in the PCF group because physical stress was not applied to the adjacent segment.

This study had a few limitations. First, there were small subjects. Second, there was a difference in the diagnoses in the ACDF group and the PCF group. That is, as ACDF and PCF are not treatment methods for the same disease, it may not be apt to compare their results for the two groups. Third, the analysis of the post-operative complications and adjacent segment disease was insufficient.

In this study, the ROM was examined only for adjacent segment degeneration. If various other factors (the disc height, osteophytes formation, signal change in the MRI, etc.) are examined, more meaningful results are expected to be obtained. In addition, if various factors that may affect the ROM are divided into subgroups and then the post-operative change in the ROM of the adjacent segment is examined for each subgroup, more meaningful results could be obtained.

\section{CONCLUSION}

As part of the long-term effects of PCF on cervical motion, the operated segment motions decreased but were preserved after PCF. However, unlikely after ACDF, the ROMs of the adjacent segment did not increase after PCF. PCF, by maintaining the motion of the operated segment, imposes less stress on the adjacent segments. This may be one of its advantages.

\section{REFERENCES}

1. Baba H, Furusawa N, Imura S, Kawahara N, Tsuchiya H,Tomita $\mathrm{K}$ : Late radiographic findings after anterior cervical fusion for spondylotic myeloradiculopathy. Spine (Phila Pa 1976) 18(15): 2167-2173, 1993

2. Bush K,Hillier S: Outcome of cervical radiculopathy treated with periradicular/epidural corticosteroid injections: a prospective study with independent clinical review. Eur Spine J 5(5): 319-325, 1996

3. Carette S,Fehlings MG: Clinical practice. Cervical radiculopathy. N Engl J Med 353(4):392-399, 2005 
4. Clarke MJ, Ecker RD, Krauss WE, McClelland RL,Dekutoski MB: Same-segment and adjacent-segment disease following posterior cervical foraminotomy. J Neurosurg Spine 6(1):5-9, 2007

5. Eck JC, Humphreys SC, Lim TH, Jeong ST, Kim JG, Hodges SD, et al.: Biomechanical study on the effect of cervical spine fusion on adjacent-level intradiscal pressure and segmental motion. Spine (Phila Pa 1976) 27(22):2431-2434, 2002

6. Fouyas IP, Statham PF,Sandercock PA: Cochrane review on the role of surgery in cervical spondylotic radiculomyelopathy. Spine (Phila Pa 1976) 27(7):736-747, 2002

7. Fuller DA, Kirkpatrick JS, Emery SE, Wilber RG,Davy DT: A kinematic study of the cervical spine before and after segmental arthrodesis. Spine (Phila Pa 1976) 23(15):1649-1656, 1998

8. Ghiselli G, Wang JC, Bhatia NN, Hsu WK,Dawson EG: Adjacent segment degeneration in the lumbar spine. J Bone Joint Surg Am 86-A(7):1497-1503, 2004

9. Goffin J, Geusens E, Vantomme N, Quintens E, Waerzeggers Y, Depreitere B, et al.: Long-term follow-up after interbody fusion of the cervical spine. J Spinal Disord Tech 17(2):79-85, 2004

10. Grieve JP, Kitchen ND, Moore AJ,Marsh HT: Results of posterior cervical foraminotomy for treatment of cervical spondylitic radiculopathy. Br J Neurosurg 14(1):40-43, 2000

11. Herkowitz HN, Kurz LT,Overholt DP: Surgical management of cervical soft disc herniation. A comparison between the anterior and posterior approach. Spine (Phila Pa 1976) 15(10):10261030, 1990

12. Hilibrand AS, Carlson GD, Palumbo MA, Jones PK,Bohlman $\mathrm{HH}$ : Radiculopathy and myelopathy at segments adjacent to the site of a previous anterior cervical arthrodesis. J Bone Joint Surg Am 81(4):519-528, 1999

13. Ishihara H, Kanamori M, Kawaguchi Y, Nakamura H,Kimura T: Adjacent segment disease after anterior cervical interbody fusion. Spine J 4(6):624-628, 2004

14. Kumar GR, Maurice-Williams RS,Bradford R: Cervical foraminotomy: an effective treatment for cervical spondylotic radiculopathy. Br J Neurosurg 12(6):563-568, 1998

15. Lind B, Sihlbom H, Nordwall A,Malchau H: Normal range of motion of the cervical spine. Arch Phys Med Rehabil 70(9): 692-695, 1989

16. Lunsford LD, Bissonette DJ, Jannetta PJ, Sheptak PE,Zorub DS: Anterior surgery for cervical disc disease. Part 1: Treatment of lateral cervical disc herniation in 253 cases. J Neurosurg 53(1): $1-11,1980$
17. Persson LC, Carlsson CA,Carlsson JY: Long-lasting cervical radicular pain managed with surgery, physiotherapy, or a cervical collar. A prospective, randomized study. Spine (Phila Pa 1976) 22(7):751-758, 1997

18. Samartzis D, Shen FH, Lyon C, Phillips M, Goldberg EJ,An HS: Does rigid instrumentation increase the fusion rate in one-level anterior cervical discectomy and fusion? Spine J 4(6):636643, 2004

19. Shin DA, Yi S, Yoon do H, Kim KN,Shin HC: Artificial disc replacement combined with fusion versus two-level fusion in cervical two-level disc disease. Spine (Phila Pa 1976) 34(11): 1153-1159; discussion 1160-1151, 2009

20. Song KJ, Choi BW, Jeon TS, Lee KB,Chang H: Adjacent segment degenerative disease: is it due to disease progression or a fusion-associated phenomenon? Comparison between segments adjacent to the fused and non-fused segments. Eur Spine J 20(11):1940-1945, 2011

21. Vedantam A, Revanappa KK,Rajshekhar V: Changes in the range of motion of the cervical spine and adjacent segments at $>/=24$ months after uninstrumented corpectomy for cervical spondylotic myelopathy. Acta Neurochir(Wien) 153(5):9951001, 2011

22. Wang MY, Green BA, Vitarbo E,Levi AD: Adjacent segment disease: an uncommon complication after cervical expansile laminoplasty: case report. Neurosurgery 53(3):770-772; discussion 772-773, 2003

23. Witzmann A, Hejazi N,Krasznai L: Posterior cervical foraminotomy. A follow-up study of 67 surgically treated patients with compressive radiculopathy. Neurosurg Rev 23(4):213-217, 2000

24. Woertgen C, Holzschuh M, Rothoerl RD, Haeusler E, Brawanski A: Prognostic factors of posterior cervical disc surgery: a prospective, consecutive study of 54 patients. Neurosurgery 40(4): 724-728; discussion 728-729, 1997

25. Yates JP, Giangregorio L,McGill SM: The influence of intervertebral disc shape on the pathway of posterior/posterolateral partial herniation. Spine (Phila Pa 1976) 35(7):734-739, 2010

26. Yue WM, Brodner W,Highland TR: Long-term results after anterior cervical discectomy and fusion with allograft and plating: a 5- to 11-year radiologic and clinical follow-up study. Spine (Phila Pa 1976) 30(19):2138-2144, 2005

27. Yukawa Y, Kato F, Suda K, Yamagata M,Ueta T: Age-related changes in osseous anatomy, alignment, and range of motion of the cervical spine. Part I: Radiographic data from over 1,200 asymptomatic subjects. Eur Spine J, 2012 